\title{
The relation between global and limbic brain volumes on MRI and cognitive performance in healthy individuals across the age range.
}

Citation for published version (APA):

Tisserand, D. J., Visser, P. J., van Boxtel, M. P. J., \& Jolles, J. (2000). The relation between global and limbic brain volumes on $\mathrm{MRI}$ and cognitive performance in healthy individuals across the age range. Neurobiology of Aging, 21, 21-21. https://doi.org/10.1016/S0197-4580(00)00133-0

Document status and date:

Published: 01/01/2000

DOI:

10.1016/S0197-4580(00)00133-0

Document Version:

Publisher's PDF, also known as Version of record

Please check the document version of this publication:

- A submitted manuscript is the version of the article upon submission and before peer-review. There can be important differences between the submitted version and the official published version of record.

People interested in the research are advised to contact the author for the final version of the publication, or visit the DOI to the publisher's website.

- The final author version and the galley proof are versions of the publication after peer review.

- The final published version features the final layout of the paper including the volume, issue and page numbers.

Link to publication

\footnotetext{
General rights rights.

- You may freely distribute the URL identifying the publication in the public portal. please follow below link for the End User Agreement:

www.umlib.nl/taverne-license

Take down policy

If you believe that this document breaches copyright please contact us at:

repository@maastrichtuniversity.nl

providing details and we will investigate your claim.
}

Copyright and moral rights for the publications made accessible in the public portal are retained by the authors and/or other copyright owners and it is a condition of accessing publications that users recognise and abide by the legal requirements associated with these

- Users may download and print one copy of any publication from the public portal for the purpose of private study or research.

- You may not further distribute the material or use it for any profit-making activity or commercial gain

If the publication is distributed under the terms of Article $25 \mathrm{fa}$ of the Dutch Copyright Act, indicated by the "Taverne" license above, 


\title{
The relation between global and limbic brain volumes on MRI and cognitive performance in healthy individuals across the age range
}

\author{
D.J. Tisserand*, P.J. Visser, M.P.J. van Boxtel, J. Jolles \\ Maastricht University, Department of Psychiatry and Neuropsychology, P.O.Box 616, 6200 MD Maastricht, The Netherlands
}

Received 15 September 1999; received in revised form 4 January 2000; 10 February 2000

\begin{abstract}
The present study investigated the range of age-related changes in brain morphology and the relation with performance on memory and other cognitive tests in a healthy population. A group of 61 subjects ( 21 to 81 years old, mean $=55.7)$, free from cognitive and medical deficits, underwent MRI scanning and neuropsychological assessment encompassing memory and other cognitive tests. Volumetry of the hippocampus, parahippocampal gyrus, mamillary bodies, third ventricle, and total brain matter was performed. The results indicate that in healthy individuals increases in ventricular volume and volume decreases in total brain matter, hippocampus and parahippocampal gyrus, but not mamillary bodies, are clearly apparent with increasing age. However, no relation could be established between the brain volumes and test performance when controlling for the effects of age. To conclude, variations in total and limbic brain volumes do not seem predictive for cognitive performance independent of age. (C) 2000 Elsevier Science Inc. All rights reserved.
\end{abstract}

Keywords: Aging; MRI; Volumetry; Limbic lobe; Memory; Cognition

\section{Introduction}

Because the proportion of elderly people has increased considerably during the last century, there is growing interest in normal and pathological changes associated with the aging process. Neuroimaging techniques such as computed tomography (CT) and magnetic resonance imaging (MRI) have substantiated the findings from postmortem studies (see [34], for a review) that nonpathological aging is associated with considerable morphological brain changes. Widening of the ventricular and sulcal liquor spaces is clearly evident in elderly persons $[2,6,8,21,22,27]$, and studies that directly measured brain volume have found age-related reductions in total and gray (but not white) matter volumes $[8,21,30,31]$. This atrophy seems to occur particularly in the frontal and temporal lobes [8,31], and also in subcortical regions [20].

With respect to cognitive functioning, especially speed of mental processing and the ability to learn and retrieve new information tend to decrease with advancing age $[1,23]$. Because cognitive processes are dependent upon the

\footnotetext{
* Corresponding author. Tel.: +31-43-3875572; fax: +31-433671096.

E-mail: d.tisserand@np.unimaas.nl (D.J. Tisserand).
}

integrity of the brain, it seems probable that changes in brain morphology (partly) account for these decreases in cognitive functioning. Studies examining patients with neurodegenerative disorders (e.g. Alzheimer's disease and Korsakoff's syndrome) have demonstrated that damage to specific brain structures is indeed related to deterioration of cognitive functions. In these studies memory impairment is often associated with atrophy of limbic structures (including hippocampus, parahippocampal gyrus [17], thalamus [38], or third ventricle [39], and mamillary bodies [36]), whereas global cognitive deficits such as slower mental processing is related to more general cerebral atrophy $[33,35]$.

Despite a considerable number of patient studies, relatively few studies with healthy volunteers have examined the relation between age-related changes in brain structures and neuropsychological test performance. No clear associations have emerged, which might be caused by a lack of adequate image analysis methods. For instance, several studies have relied only on global atrophy measures such as ventricular dilatation $[4,22]$, whereas others focused on specific brain regions but used qualitative rating scales to assess severity of atrophy $[9,12]$. Only two studies have investigated the relation between regional brain atrophy and $\operatorname{cog}$ nitive deterioration using quantitative (i.e. volumetric) analysis methods in a large sample [14,32]. A relation was 
found between limbic structures and memory in subjects over 55 years of age.

In the present study a group of healthy subjects with a wide age-range was examined using both MRI and a number of neuropsychological tests. The aim of this research was twofold. First, we wanted to establish the range of nonpathological changes in brain regions known to be involved in memory across the adult age spectrum. Volumetry of the hippocampus, parahippocampal gyrus, mamillary bodies, third ventricle, and total brain matter was performed. Secondly, we investigated whether normal agerelated cognitive decline can be explained by volume changes. The general hypothesis was that volume reductions in limbic structures (hippocampus, parahippocampal gyrus and mamillary bodies; and dorsomedial thalamus as indexed by the third ventricle [19]) are especially related to lower scores on memory tests, whereas decreases in total brain volume are related to slower performance on speed tasks. Furthermore, although advancing age is accompanied by decreases both in brain volumes and in test performance, it was expected that the volume-performance associations were only partially mediated by age.

\section{Methods}

\subsection{Subjects}

The study sample comprised 61 healthy and cognitively normal persons, aged 21 to 81 years (mean $\pm \mathrm{SD}=55.7 \pm$ 16.1). The group consisted of 35 men (mean $\pm \mathrm{SD}=$ $53.5 \pm 2.7$ ) and 26 women (mean $\pm \mathrm{SD}=58.6 \pm 3.1$ ). Mean educational level, as measured on a five-point scale $(1=$ primary school, $5=$ university degree $)$, was $2.6(\mathrm{SD}=$ 1.1). Subjects were rigorously screened and excluded if there was a history of cerebrovascular (e.g. stroke) or chronic neurological disease (e.g. dementia, epilepsy, head trauma), systemic disorders (e.g. diabetes mellitus), or major psychiatric illnesses using health questionnaires and interviews.

\subsection{MRI acquisition and analysis}

All subjects were imaged using a 1.5 T Gyroscan ACS-II MRI scanner (Philips, Best, The Netherlands). T1 weighted images were acquired in the coronal plane (perpendicular to the anterior commissure-posterior commissure line). A 3D gradient fast field echo (FFE) sequence was applied with $\mathrm{TR}=23 \mathrm{~ms}$ and $\mathrm{TE}=7 \mathrm{~ms}$, and a flip angle of $30^{\circ}$. Slice thickness was $1.5 \mathrm{~mm}$ with no interslice gap. The image matrix was $256 \times 256$ and the field of view $230 \mathrm{~mm}$.

Intracranial volume (including the cerebellum) was automatically determined (in $\mathrm{mm}^{3}$ ) on all slices using custom software developed at the Department of Medical Informatics of the Universiteit Maastricht, The Netherlands, running on a G3 MacIntosh workstation (Apple, Cupertino, CA,
USA). This procedure generates a contour around all neural tissue, excluding the meninges and bone structures. All structures below the pons were manually excluded from the measurements. After that, using the program BrainImage (Kennedy Krieger Institute, Baltimore, MD, USA) the total brain volume was determined (in $\mathrm{mm}^{3}$ ) with an automated segmentation algorithm [29]. This algorithm calculates the mean gray-level intensity of white matter, gray matter and liquor, and the cut-off value between liquor and gray matter was used to separate brain from non-brain.

The other brain volumes were determined using custom software developed at the Department of Clinical Physics and Informatics of the Vrije Universiteit Amsterdam, the Netherlands, running on a SUN workstation (SUN Microsystems, Mountain View, CA, USA). All brain structures were manually traced. In all cases, demarcation criteria (see below) were determined by consulting anatomical atlases $[10,28]$. The criteria that were applied for measurement are described in detail elsewhere [39]. In short, the hippocampus was measured every other slice in both hemispheres (range of measurements: 8-13) and included the hippocampus proper, dentate gyrus, alveus, and subiculum. Left and right surfaces were calculated separately as well as together. Measurements were started anteriorly on the first slice where the hippocampus and amygdala were clearly separated, and the last slice was the slice before the crura of the fornices became visible. The parahippocampal gyrus was measured every other slice in both hemispheres, on the same slices on which the hippocampus was measured. The upper boundary was formed by the hippocampus or transverse fissure, and the lateral boundary consisted of the collateral sulcus. Left and right surfaces were calculated separately as well as together. The mamillary bodies were seen on three or four slices, and were measured on each of those. The third ventricle was measured on each slice on which it appeared (range: 15-19) using a threshold pixel value. The anterior border was defined as the first slice where the optic chiasma was clearly connected to the diencephalon. The last slice was the slice before the posterior commissure became visible. Surfaces of the measurements were calculated automatically (in $\mathrm{mm}^{2}$ ), and volumes were computed by multiplying the surfaces with the slice thickness, or twice the slice thickness in case of the hippocampus and parahippocampal gyrus. Fig. 1 shows a typical image with various brain regions outlined.

Each brain structure was assigned to only one rater. Measurements were performed blind, i.e. raters were unaware of subject characteristics. To establish that measurements were sufficiently reliable, on ten scans all volumes of interest (VOIs) were remeasured after several weeks by the same investigator. The Pearson correlation coefficient between the first and second measurements was 0.91 for the hippocampus, 0.91 for the parahippocampal gyrus, 0.86 for the mamillary bodies, 0.98 for the third ventricle, 1.0 for the total brain matter, and 1.0 for the intracranial volume. These 


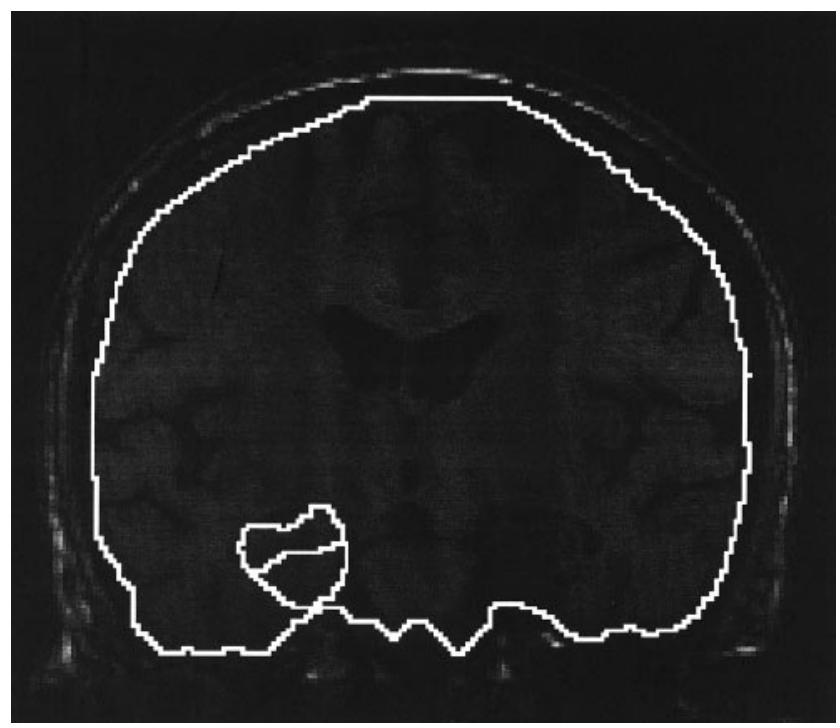

Fig. 1. Coronal MR image, illustrating measurement of the intracranial volume, and right hippocampus (top) and parahippocampal gyrus (bottom).

correlations indicate a high level of intrarater agreement for all measurements.

\subsection{Neuropsychological assessment}

Tests were aimed at measuring memory (Word Learning Test) on the one hand, and speed of mental processing (Memory Scanning Test, Stroop Color-Word Test) on the other.

- In the Word Learning Test a list of 15 monosyllabic words is auditorily presented to the subjects $5 \times$ and after each trial they are asked to recall as many words as possible. The total score of all trials is taken as a measure for learning ability (WLT total). After a time interval of 20 to 30 min subjects are asked again to recall as many words as possible (WLT recall) [3].

- The Memory Scanning Test is a paper and pencil cancellation test that consists of 12 rows of 12 letters and numbers, randomly interspersed with a target symbol or letter that subjects have to cross out. The cognitive load can be enhanced by increasing the number of targets that need to be memorized [3]. In the present study, two target sets were used: one with one target symbol (MST\%) and one with three letters (MST3), and the time needed for completion was recorded.

- In the Stroop Color-Word Test a sheet is presented consisting of a $10 \times 10$ matrix with colored patches and subjects have to name them as fast as possible (Stroop Card 1). Subsequently, a sheet is presented consisting of a $10 \times 10$ matrix with color names printed in a different color of ink. Subjects have to name the color of ink as fast as possible, which requires the inhibition of reading the words themselves (Stroop Card 3) [16]. Time needed for completion was recorded.

\subsection{Statistical analysis}

To take intersubject variation in head size into account all VOIs were regressed on the intracranial volume. These adjusted volumes were then used for further analysis. Age was regressed on the adjusted brain volumes to investigate linear or higher order correlations. The contribution of a quadratic age component was examined by means of the $\mathrm{R}^{2}$ change when age and age $^{2}$ were entered into the model successively (whereas correcting for collinearity between those variables, according to the method described in [11]). To test whether the regional volume changes exceeded that of the total brain, total brain volume and age were entered successively into a model with regional brain volume as the dependent variable.

Furthermore, hierarchical regression models were created with the neuropsychological test results as dependent variables. Gender and educational level were treated as covariates and were entered in the first step. In one model, the adjusted VOIs were entered in the second step. In another model, the second entry consisted of age, or age + age $^{2}$ (beneficial in the case of speed tests), whereas in the final step the adjusted brain volumes were entered.

\section{Results}

\subsection{Relations between VOIs and age}

Men had significantly larger intracranial volumes than women (1071 versus $\left.957 \mathrm{~cm}^{3}, P<0.001\right)$. Because of this difference, and because brain structures and intracranial size are related [15] all VOIs were adjusted for intracranial volume. In none of the cases did either gender or education add significantly to the model, so these variables were not considered any further. Associations between the adjusted brain volumes and age were assessed in hierarchical regression analyses. A summary of the measurements and their relation with age is presented in Table 1 and in Fig. 2.

A quadratic effect of age was found for the total brain volume $(r=-0.80, P<0.001)$. A similar quadratic pattern was found for the total volume of the parahippocampal gyrus $(r=-0.54, P<0.001)$. This volume reduction was significant for both the left $(r=-0.57, P<0.001)$ and the right hemisphere $(r=-0.38, P<0.01)$. A linear relation was found between volume of the hippocampus and age (total: $r=-0.35$, left: $r=-0.35$, right: $r=-0.30 ; P<$ $0.05)$. The third ventricle volume also increased linearly with age $(r=0.61, P<0.001)$. Finally, the volume of the mamillary bodies showed no age-related changes $(r=0.17$, ns.). In addition, it was investigated whether the regional volume changes were disproportional compared to the global atrophy. This was the case for none of the regions, which indicates that regional volume reductions were not greater than expected given the decrease in total brain volume. 
Table 1

Brain volumes $\left(\mathrm{mm}^{3}\right)$, adjusted for intracranial volume, and their relation with age (Pearson product-moment correlations).

\begin{tabular}{|c|c|c|c|c|}
\hline & Mean & (SD) & $\min -\max$ & $r$ (age) \\
\hline Total brain matter & 821743 & $(35281)$ & $735722-870930$ & $-0.78 * * *$ \\
\hline Hippocampus & 2929.4 & $(372)$ & 2112-3805 & $-0.32 *$ \\
\hline Left & 1427.1 & (205) & $975-1969$ & $-0.33^{*}$ \\
\hline Right & 1501.4 & (189) & $1135-1899$ & $-0.28 *$ \\
\hline Parahippocampal gyrus & 4629.4 & (595) & $3426-5802$ & $-0.42 * * *$ \\
\hline Left & 2395.8 & (328) & $1741-3184$ & $-0.42 * * *$ \\
\hline Right & 2339.3 & (309) & $1738-3115$ & $-0.36^{* *}$ \\
\hline Mammillary bodies & 67.5 & (10) & $51-90$ & 0.17 \\
\hline Third ventricle & 874.7 & $(362)$ & $314-1711$ & $0.61 * * *$ \\
\hline
\end{tabular}

$* P<0.05 ; * * P<0.01 ; * * * P<0.001$

\subsection{Relations between VOIs and neuropsychological test performance}

To account for possible influence of gender and educational level on test performance, these variables were treated as covariates in all models. The relation between VOIs and cognitive functioning was examined in two models. In a model without accounting for the effects of age (Table 2) highly significant relations were found between all brain volumes (except mamillary bodies) and various tests of processing speed, all in the predicted direction (i.e. smaller brain volumes and larger ventricular volumes were related to poorer test scores). Volumes of the hippocampus and parahippocampal gyrus were related to performance on both subtasks of the Memory Scanning Test and Card 1 of the Stroop Test. Total brain and ventricular volumes were related to performance on both subtasks of the Memory Scanning Test and the Stroop Test. With respect to memory, a significant association was found between learning ability (WLT total) and volumes of total brain matter, parahip-
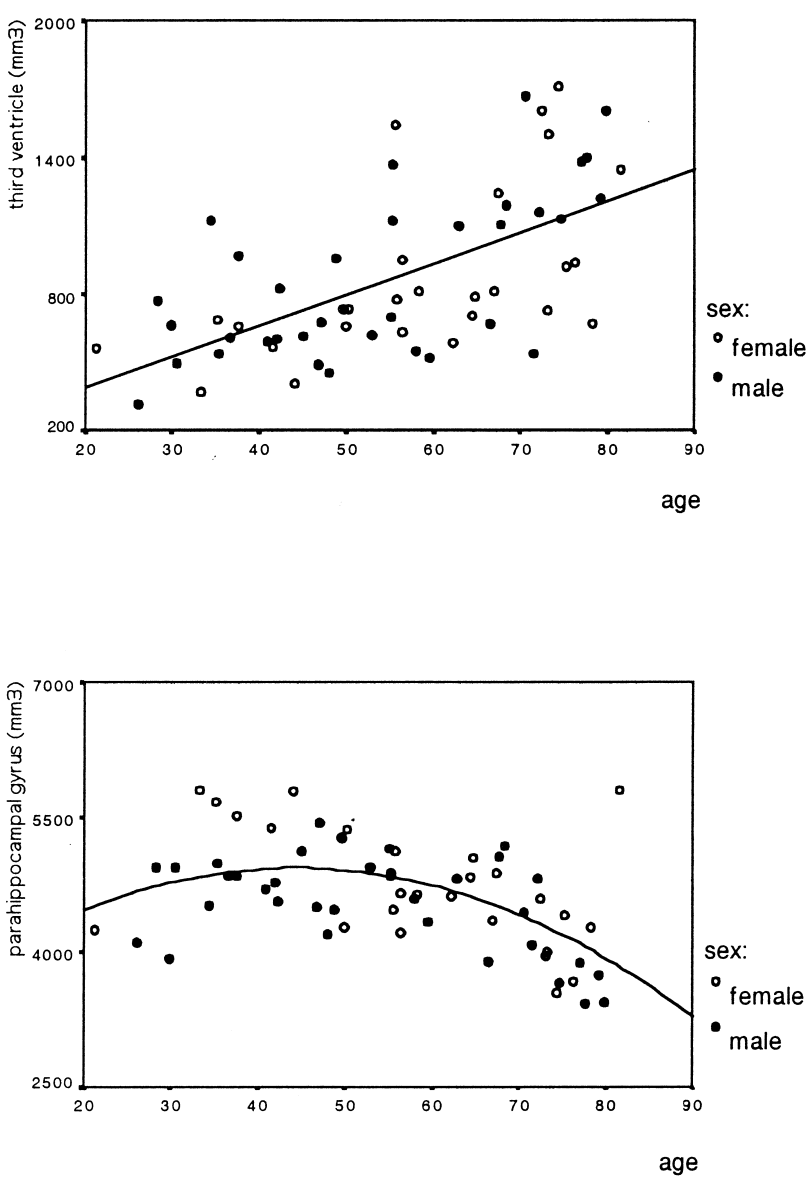

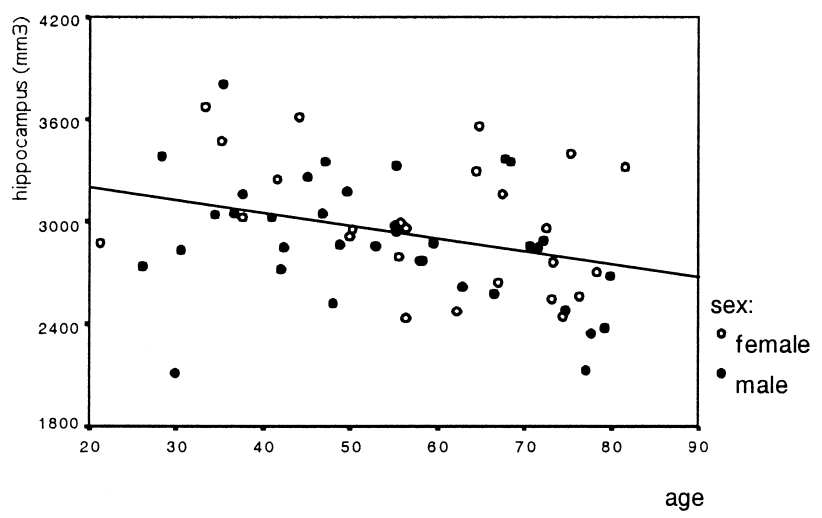

Fig. 2. Age-related changes in brain volumes in men $(\mathbf{O})$ and women $(\bigcirc)$. 
Table 2

Results of hierarchical regression analysis. Sex and education were entered in the first step, followed by the brain volumes. Displayed is the proportion of explained variance $\left(R^{2}\right)$ and the significance of the $R^{2}$ change after each step.

\begin{tabular}{|c|c|c|c|c|c|c|}
\hline & \multirow{2}{*}{$\begin{array}{l}\text { Step } 1 \\
\text { gender }+ \\
\text { education }\end{array}$} & \multicolumn{5}{|l|}{ Step 2} \\
\hline & & hippocampus & parahippocampal gyrus & mammillary bodies & third ventricle & total brain matter \\
\hline MST \% & 0.08 & $0.22 * *$ & $0.29 * * *$ & 0.08 & $0.39 * * *$ & $0.55^{* * * *}$ \\
\hline MST 3 & $0.12 *$ & $0.19 *$ & $0.25 * *$ & 0.14 & $0.25 * *$ & $0.43 * * *$ \\
\hline Stroop 1 & 0.09 & $0.22 * *$ & $0.23 * *$ & 0.11 & $0.20 * *$ & $0.24 * *$ \\
\hline Stroop 3 & 0.09 & 0.13 & 0.15 & 0.14 & $0.29 * * *$ & $0.34 * * *$ \\
\hline WLT total & $0.18^{*}$ & 0.18 & $0.24 *$ & 0.18 & $0.28 * *$ & $0.33^{* * *}$ \\
\hline WLT recall & 0.06 & 0.06 & 0.10 & 0.07 & $0.13 *$ & $0.17 * *$ \\
\hline
\end{tabular}

MST, memory scanning task; WLT, word learning test.

$* P<0.05 ; * * P<0.01 ; * * * P<0.001$

pocampal gyrus and third ventricle. Delayed recall was only correlated with total brain volume. Other associations were not significant.

To investigate to what extent age obscured this relation between brain volumes and test performance, a second model controlling the effects of age was examined (Tables 3 and 4). As expected, after controlling for gender and education, age explained a large proportion of the variance, varying between $8 \%(P<0.05)$ for the WLT recall and $66 \%(P<0.001)$ for the MST\% task. However, the regions of interest no longer significantly added to the explained variance after age was entered. Only in one case (i.e., total brain volume and MST3) did the model significantly improve after entering the region of interest $(P<0.05)$.

\section{Discussion}

The main hypothesis of the present study was that smaller brain volumes and larger ventricular volumes are related to reductions in neuropsychological test performance. Indeed, a relation was found between most regions of interest and various processing speed and memory tests. However, it was expected that this effect would still hold when controlling the effects of age, but this was not the case. Although higher age is clearly associated with larger ventricular volumes and smaller total brain regions and volumes of brain structures involved in memory processes, these volume variations do not seem predictive for neuropsychological test performance independent of age.

\subsection{Normal brain aging}

The present cross-sectional study demonstrates that normal aging is associated not only with losses in total brain volume, but also with local atrophy of brain regions important for memory. The total brain volume showed a quadratic relation with age, which is consistent with previous reports (e.g. $[2,6,27])$. However, there is still debate as to whether normal aging is necessarily accompanied by atrophy of limbic memory structures. Volumes of hippocampus and parahippocampal gyrus were found to decline significantly with age. Several authors have reported similar age-related volume decreases in these regions $[8,9,12,18,26,31]$. However, other authors have failed to find such a decline in medial temporal lobe volumes [24,31,37]. Linear increases with advancing age were found for the volume of the third ventricle (taken as an index for atrophy of the dorsomedial thalamus [19]). This is consistent with previous reports (e.g. $[2,6,27])$. In line with earlier findings [5] volumes of the

Table 3

Results of hierarchical regression analysis. Sex and education were entered in the first step, age (and age ${ }^{2}$ ) in the second step, and finally the brain volumes. Displayed is the proportion of explained variance $\left(\mathrm{R}^{2}\right)$ and the significance of the $\mathrm{R}^{2}$ change after each step.

\begin{tabular}{|c|c|c|c|c|c|c|c|}
\hline & \multirow{2}{*}{$\begin{array}{l}\text { Step } 1 \\
\text { gender }+ \\
\text { education }\end{array}$} & \multirow{2}{*}{$\frac{\text { Step } 2}{\text { age }+ \text { age }^{2}}$} & \multicolumn{5}{|l|}{ Step 3} \\
\hline & & & hippocampus & parahippocampal gyrus & mammillary bodies & third ventricle & total brain matter \\
\hline MST \% & 0.08 & $0.74 * * *$ & 0.74 & 0.74 & 0.74 & 0.74 & 0.74 \\
\hline MST 3 & $0.12^{*}$ & $0.40 * * *$ & 0.41 & 0.42 & 0.41 & 0.40 & $0.45^{*}$ \\
\hline Stroop 1 & 0.09 & $0.26^{* *}$ & 0.30 & 0.29 & 0.28 & 0.28 & 0.28 \\
\hline Stroop 3 & 0.09 & $0.43 * *$ & 0.44 & 0.45 & 0.46 & 0.45 & 0.44 \\
\hline WLT total & $0.18^{*}$ & $0.29 * *$ & 0.31 & 0.30 & 0.29 & 0.31 & 0.33 \\
\hline WLT recall & 0.06 & $0.14 *$ & 0.17 & 0.15 & 0.14 & 0.16 & 0.17 \\
\hline
\end{tabular}

MST, memory scanning task; WLT, word learning test.

$* P<0.05$, ** $P<0.01 ; * * * P<0.001$. 
Table 4

Two examples of regression analyses of the partial model (gender, education and brain volume) and the full model (gender, education, brain volume and age). Shown are the regression coefficients (beta) and the associated $p$-values. Dependent variables are the neuropsychological tests.

\begin{tabular}{lcc}
\hline & Partial model & Full model \\
\hline MST \% & & \\
Gender & $0.19^{*}$ & -0.02 \\
Education & -0.14 & -0.04 \\
Total brain matter & $-0.71^{* * *}$ & -0.09 \\
Age & & $0.75^{* * *}$ \\
Age & & $0.19^{*}$ \\
WLT total & & $0.43^{* * *}$ \\
Gender & $0.36^{* *}$ & 0.02 \\
Education & 0.13 & 0.11 \\
Parahippocampal gyrus & $0.25^{*}$ & $-0.31^{*}$ \\
Age & & \\
\hline
\end{tabular}

MST, memory scanning task; WLT, word learning test.

$* P<0.05, * * P<0.01, * * * P<0.001$.

mamillary bodies were not significantly correlated with age. No gender or educational differences were found for any of the brain volumes, which is in line with other findings [6,7].

Because of the marked age-related reduction in total brain volume, it was examined whether the regional volume decreases were disproportional compared to the global reductions. Other studies have reported that frontal and temporal association areas are particularly affected by advancing age [8,20,31]. In this study, none of the regional volume reductions were greater than expected given the decrease in total brain volume. This may indicate that volume decreases in limbic regions are not specific for the aging process and are simply part of more global age-related volume losses.

\subsection{Relation between brain volumes and cognitive performance}

In the present study the hypothesis was tested that agerelated declines in cognitive functioning are associated with changes in brain morphology. Based upon what is known from patient studies (e.g. [17,33,38,39]), it was expected that reductions in total brain volume would be related to a decline in performance on global cognitive tests measuring speed of mental processing, whereas atrophy of limbic structures (hippocampus, parahippocampal gyrus and mamillary bodies; and third ventricle as an index for the dorsomedial thalamus [19]) would be specifically associated with a deterioration on memory tests. We found a somewhat different pattern. All volumes except that of the mamillary bodies showed a relation with tests measuring speed of processing. In addition, volumes of the parahippocampal gyrus and third ventricle were associated with learning ability. Total brain volume was related to both learning ability and delayed recall. All these relations were in the expected direction.

Not surprisingly, (see for instance $[1,23]$ ) increasing age was found to be strongly associated with poorer performance on all speed and memory variables. Therefore we separately investigated the relation between brain volumes and cognitive performance after partialling out the influence of age. After correcting for age the volumes no longer significantly added to the explained variance. In other words, when age-related variance in test performance was taken into account, total and limbic brain volumes were not predictive for cognitive performance.

How can these findings be interpreted? First, a general remark is that inferences that can be drawn from crosssectional studies such as the present one are rather limited. For instance, age-related brain atrophy may slightly precede cognitive deterioration in time and therefore seem unrelated to it. Indeed, two recent studies showed that medial temporal lobe volume at baseline significantly predicted longitudinal change on memory tests $[13,40]$. Only longitudinal research can clarify the issue of whether age-related losses in brain volumes necessarily lead to cognitive decline.

Second, the lack of volumetry-performance associations after accounting for age may be due to the broad age-range of the present sample. In two other studies with subjects aged 18 to 80 years no relation could be established between brain volumes and neuropsychological test results after controlling for the effects of age [22,32]. However, in studies where only $55+$ subjects were included a significant relation was found between limbic structures and memory test performance [13,14,32]. Perhaps in older subjects, in whom both cognitive decline and brain atrophy are more obvious, the relation between the two is also stronger. Therefore, in the present study post-hoc analyses were performed to examine whether volumetry-performance associations could be established in subjects over 55 years $(n=35)$. Again, no significant relations were found when accounting for the effects of age.

A third explanation, related to the previous one, might be that cognitive functions are affected only by substantial volume losses, and that a threshold must be passed before atrophy leads to performance decline. For instance, in two studies by Golomb and coworkers $[9,12]$ healthy elderly subjects with visually rated hippocampal atrophy were found to perform significantly worse on memory tests than subjects without atrophy and this relation was unrelated to age. The subjects in the present study were included only when they were free of cognitive deficits and may therefore not be representative for the population as a whole. Perhaps the subjects of Golomb et al. performed less 'successfully' (but within normal range) and had more prominent brain atrophy than the ones in the present study.

Finally, a completely different explanation for our findings is that the age-related decreases in test performance are not related to volume decreases in limbic structures or the brain as a whole, but to atrophy of other areas not measured in this study, or a combination of several of these regions. For instance, a region that is frequently reported to show disproportional volume losses during the nonpathological aging process 
is the prefrontal cortex $[8,20,31]$. Several authors have even suggested that age-related cognitive deterioration is principally the consequence of alterations in prefrontal structure and function (e.g. $[25,41])$. Therefore, future research should try to explore also other than limbic brain areas involved in cognition, such as prefrontal regions, and when possible MR scanning should be repeated in the same individuals. Only then can firm conclusions be drawn about regional brain volume losses and their contribution to cognitive aging.

\section{Aknowledgments}

We thank Dr E. Gronenschild for his technical support.

\section{References}

[1] Birren JE, Schroots JJF. History, concepts, and theory in the psychology of aging. In: Birren JE, Schaie KW, editors. Handbook of the psychology of aging, 4th edition. San Diego: Academic Press, 1996. p. 3-23.

[2] Blatter DD, Bigler ED, Gale SD, et al. Quantitative volumetric analysis of brain MR: normative database spanning 5 decades of life. Am J Neuroradiol 1995;16:241-51.

[3] Brand N, Jolles J. Learning and retrieval rate of words presented auditorily and visually. J Gen Psychol 1985;112:201-10.

[4] Breteler MM, van Amerongen NM, van Swieten JC, et al. Cognitive correlates of ventricular enlargement and cerebral white matter lesions on magnetic resonance imaging. The Rotterdam Study. Stroke 1994;25:1109-15.

[5] Charness ME, De La Paz RL. Mamillary body atrophy in Wernicke's encephalopathy: antemortem identification using magnetic resonance imaging. Ann Neurol 1987;22:595-600.

[6] Coffey CE, Lucke JF, Saxton JA, et al. Sex differences in brain aging: a quantitative magnetic resonance imaging study. Arch Neurol 1998; 55:169-79.

[7] Coffey CE, Saxton JA, Ratcliff G, Bryan RN, Lucke JF. Relation of education to brain size in normal aging: implications for the reserve hypothesis [In Process Citation]. Neurology 1999;53:189-96.

[8] Coffey CE, Wilkinson WE, Parashos IA, et al. Quantitative cerebral anatomy of the aging human brain: a cross-sectional study using magnetic resonance imaging. Neurology 1992;42:527-36.

[9] De Leon MJ, George AE, Golomb J, et al. Frequency of hippocampal formation atrophy in normal aging and Alzheimer's disease. Neurobiol Aging 1997;18:1-11.

[10] Duvernoy H. The human brain: surface, three-dimensional sectional anatomy and MRI. Vienna: Springer, 1991.

[11] Earles JL, Connor LT, Smith AD, Park DC. Interrelations of age, self-reported health, speed, and memory. Psychol Aging 1997;12: 675-83.

[12] Golomb J, De Leon MJ, Kluger A, George AE, Tarshish C, Ferris SH. Hippocampal athrophy in normal aging: an association with recent memory impairment. Arch Neurol 1993;50:967-73.

[13] Golomb J, Kluger A, De Leon MJ, et al. Hippocampal formation size predicts declining memory performance in normal aging. Neurology 1996;47:810-3.

[14] Golomb J, Kruger A, De Leon MJ, et al. Hippocampal formation size in normal human aging: a correlate of delayed secondary memory performance. Learn Memory 1994;1:45-54.

[15] Gould SJ. The mismeasure of man. New York: W. W. Norton, 1981.
[16] Houx PJ, Jolles J, Vreeling FW. Stroop interference: aging effects assessed with the Stroop Color-Word Test. Exp Aging Res 1993;19: 209-24.

[17] Jack CR Jr, Petersen RC, O'Brien PC, Tangalos EG. MR-based hippocampal volumetry in the diagnosis of Alzheimer's disease. Neurology 1992;42:183-8.

[18] Jack CRJ, Petersen RC, Xu YC, et al. Medial temporal atrophy on MRI in normal aging and very mild Alzheimer's disease. Neurology 1997;49:786-94.

[19] Jacobson RR, Lishman WA. Cortical and diencephalic lesions in Korsakoff's syndrome: a clinical and CT scan study. Psychol Med 1990;20:63-75.

[20] Jernigan TL, Archibald SL, Berhow MT, Sowell ER, Foster DS, Hesselink JR. Cerebral structure on MRI, part I: localization of age-related changes. Biol Psychiatry 1991;29:55-67.

[21] Jernigan TL, Press GA, Hesselink JR. Methods for measuring brain morphologic features on magnetic resonance images. Arch Neurol 1990;47:27-32.

[22] Kaye JA, DeCarli C, Luxenberg JS, Rapoport SI. The significance of age-related enlargement of the cerebral ventricles in healthy men and women measured by quantitative computed X-ray tomography. J Am Geriatr Soc 1992;40:225-31.

[23] La Rue A. Aging and neuropsychological assessment. New York: Plenum Press, 1992.

[24] Lim KO, Zipursky RB, Murphy GMJ, Pfefferbaum A. In vivo quantification of the limbic system using MRI: effects of normal aging. Psychiatry Res 1990;35:15-26.

[25] Moscovitch M, Winocur G. Frontal lobes, memory, and aging. Ann NY Acad Sci 1995;769:119-50.

[26] Mu Q, Xie J, Wen Z, Weng Y, Shuyun Z. A quantitative MR study of the hippocampal formation, the amygdala, and the temporal horn of the lateral ventricle in healthy subjects 40 to 90 years of age. Am J Neuroradiol 1999;20:207-11.

[27] Murphy DGM, DeCarli C, Schapiro MB, Rapoport SI, Horwitz B. Age-related differences in volumes of subcortical nuclei, brain matter, and cerebrospinal fluid in healthy men as measured with magnetic resonance imaging. Arch Neurol 1992;49:839-45.

[28] Nieuwenhuys R, Voogd J, Van Huijzen C. The human central nervous system: a synopsis and atlas. Berlin: Springer, 1981.

[29] Otsu N. A threshold selection method from gray-level histograms. IEEE Trans Sys Man Cyber 1979;9:62-6.

[30] Pfefferbaum A, Mathalon DH, Sullivan EV, Rawles JM, Zipursky RB, Lim KO. A quantitative magnetic resonance imaging study of changes in brain morphology from infancy to late adulthood. Arch Neurol 1994;51:874-87.

[31] Raz N, Gunning FM, Head D, et al. Selective aging of the human cerebral cortex observed in vivo: differential vulnerability of the prefrontal gray matter. Cereb Cortex 1997;7:268-82.

[32] Raz N, Gunning-Dixon FM, Head D, Dupuis JH, Acker JD. Neuroanatomical correlates of cognitive aging: evidence from structural magnetic resonance imaging. Neuropsychology 1998;12:95-114.

[33] Seab JP, Jagust WJ, Wong ST, Roos MS, Reed BR, Budinger TF. Quantitative NMR measurements of hippocampal atrophy in Alzheimer's disease. Magn Reson Med 1988;8:200-8.

[34] Selkoe DJ. Aging brain, aging mind. Sci Am 1992;267:97-103.

[35] Shear PK, Sullivan EV, Mathalon DH, et al. Longitudinal volumetric computed tomographic analysis of regional brain changes in normal aging and Alzheimer's disease. Arch Neurol 1995;52:392-402.

[36] Squire LR, Amaral DG, Press GA. Magnetic resonance imaging of the hippocampal formation and mammillary nuclei distinguish medial temporal lobe and diencephalic amnesia. J Neurosci 1990;10:310617.

[37] Sullivan EV, Marsh L, Mathalon DH, Lim KO, Pfefferbaum A. Age-related decline in MRI volumes of temporal lobe gray matter but not hippocampus. Neurobiol Aging 1995;16:591-606. 
[38] Victor M, Adams RD, Collins GH. The Wernicke-Korsakoff syndrome and related neurologic disorders due to alcoholism and malnutrition. Philadelphia: Davis, 1989.

[39] Visser PJ, Krabbendam L, Verhey FRJ, et al. Brain correlates ofmemory dysfunction in alcoholic Korsakoff's syndrome. J Neurol Neurosurg Psychiatry 1999;67:774-8.
[40] Visser PJ, Scheltens P, Verhey FRJ, et al. Medial temporal lobe atrophy and memory dysfunction as predictors for dementia in subjects with mild cognitive impairment. J Neurol 1999;246:47785 .

[41] West RL. An application of prefrontal cortex function theory to cognitive aging. Psychol Bull 1996;120:272-92. 